\section{Rethinking the Binary of Pure Objectivity and Relativistic Chaos}

ABSTRACT: This paper seeks to refute some of the common presuppositions of traditional Western epistemologies, which center on the claim that subjectivity cannot be as truth-yielding as "objectivity." This paper argues that aspects of the subjective can effectively be utilized in a valid epistemology attempting to approach an understanding of the truth of lived human experience-i.e. that subjectivity can in certain circumstances be as truth-yielding as, or even more so than, the epistemic ideal of objectivity. Ultimately, this paper concludes that the objective-subjective epistemic binary is artificial and disadvantageous in that neither pure objectivity nor absolute relativity are possible.

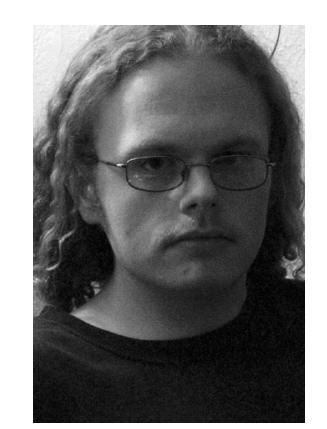

Jason Huber is a graduating senior at Case Western Reserve University in Cleveland, Ohio where he is triple-majoring in Philosophy, Art History, and Women's and Gender Studies. His personal-familial experiences with poverty and systemic social inequity have fundamentally affected his philosophic interests. He firmly believes that thought should be founded in experience and should be concerned with enabling the development of stronger, more reliable person-to-person and person-to-world connections. His philosophy is oriented towards social and political change, activism, and personal enrichment. His

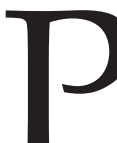

aps the most ubiquitous epistemic convention in the West, an entrench remnant of Enlightenment science an philosophy, is the oppositional duality of objectivity and subjectivity (traditionally associated with reason and affect, respectively). These two faculties/properties of the huma exclusive in most epistemic endeavors, and any pursuit that involves emotions in any way is seen as epistemically less valuable or less "true." This epistemic assumption is made manifest in the separation and hierarchization of the natura sciences and the social sciences and humanities. It seems to be a mainstream assumption that the disposition are tacitly assumed to be mutually less of a right to claims to truth than the natural sciences, specifically because subjective experience and interpretation purportedly play a more central role in their methodologies. Indeed, "Anything too tightly associated with emotion and desire, it turn out, is metaphysically a second-class citizen." ${ }^{2}$ Just what is it that the West fears in attributing truth to subjective experiences and emotions? Why is "objectivity" more epistemically valid for truth claims than "subjectivity"? 3 And is "objectivity" truly objective; are objectivity and subjectivity mutually exclusive? And if not, why would this be a problem? Can anything epistemically relevant be found in subjectivity? It is the goal of this paper to explore these epistemological issues by critically reviewing conventional valuations of 'objectivity' as well as to provide a feminist epistemologica critique of the hierarchical separation of objectivity and subjectivity. I will defend the role of the subjective-as both an aspect of methodology an as a "truth-yielding" object of study-in a valid and equitable epistemology that seeks to approac the truth of lived human experience.

I think it would be fair to say that the ultimate I think it would be fair to say thather ective in Western epistemology is because of apprehension concerning relativistic chaos. Since objectivity and subjectivity are so diametrically opposed, just the hint of subjective experience in any intellectual pursuit immediately threaten that pursuit's capacity to make any claim to the truth about "reality-as-such." The conventional foundationalist and positivist viewpoints that to conceive of truth as that which is universally valid or derived inductively therefrom. ${ }^{4}$ Therefore, it is implicitly claimed that introducing the personal invalidates proposition's stake in the claim of universal validity, and thus truth. The concern is that the introduction of the personal (into methodology, interpretation, etc.) will ultimately effect an epistemic reduction to absolute relativism, and no claims to the truth can be made at such poin by any episten blanketasumption that all lains to truth must be divested as bestas posible of truth must

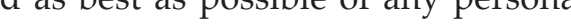
vestige of the claimant-including gender. Noting that the primary claim of feminis epistemologists is that the category of gender influences all of our knowledge-pursuing and producing activities, this is clearly a problem. Given the rigorous demands to objectivity typical of positivist science-such as those proposed by the Vienna Circle or philosopher following them, e.g. A.J. Ayer ${ }^{5}$ - it is reasonable ity, which are (b) expressed free from the influence of personal bias and (c) put forth by a detached, rational knowledgeclaimant-the Enlightenment ideal of the detached, rational observer. Subjectivity as dealt with in this paper has two significant meanings: first, the personal (affective, experiential, social, etc.). aspects of the researcher's life and work; of subjectivity will be defended in this paper.

4. For a case for strong foundationalism, see Roderick M. Chisholm, Theory of Knowledge (Edgewood Cliffs, NJ: Prentice-Hall, 1966). He puts forth perhaps the best argument for a strong foundationalism founded in basic beliefs that are either self-evident or incorrigible,

5. For further information concerning logical positivism, please see A.J. Ayer, Language, Truth, and Logic (New York 
to ask: is "objectivity" as practiced (assumed?) kind of evidence constitutes legitimate data, in the natural sciences actually devoid of any and so on, will all be affected by our social trace of the individual pursuing these studies? situation-not least of which are our race, class, Sandra Harding's work on this question is sexual orientation, gender, and nationality, all of particularly elucidating here. She is right to ask, which have associated sociocultural values and expectations. What we define as problematic, If gender is a variable in the most formal or more broadly as intellectually interesting, structures of beliefs about the boundaries is necessarily affected by our cultural context. between nature and culture, or the The pursuit of biomedical engineering projects fundamental constituents of socially that attempt to improve, say, the versatility of constructed realities, why should we assume prosthetic limbs would be logically inconceivable if that the formal structures of natural science we did not live in a culture where some people belief are immune?"

To begin, the very ideal of completely detached and impartial objectivity may itself be gendered presupposition. An obsession with the quantitative and a devaluation of the qualitative may simply be a manifestation of the preference of "objective" reason over the "subjective" affect. Since qualitative judgment seems necessarily to involve a degree of subjective interpretation, it is not seen as "purely" objective as quantitative measurement is assumed to be.

Even if we were to humor this assumptionthat theideal of objectivity is sound, desirable, and unbiased-natural science will still inevitably run into instances of subjective influence. No matter how abstracted from our subjective experien numbers, theories, and measurements may be, we as the collectors of numbers, the formulators of theories, and the makers of measurements are subjective beings. The questions we ask the forms of knowledge we value, the theories we validate with the evidence we collect, what are missing limbs and where this is seen as a problem that demands a solution. Likewise, to use a more gender-specific example, we would not be pursuing medical "remedies" to PMS if we did not already view the physiogical changes that wonten under before and during their menstrul cycles problematic. "Objectivity," then, is not as objective in the natural sciences as it is made out to be.

What can be done to change this-to approach the truth more 'directly' by becoming aware of subjective bias in our "objective" pursuits? Since the natural sciences have been construc to utilize a self-correcting empirical methodology, what is needed is a feminist epistemological critique that functions within the accepted methodology of the sciences. Enter feminist epistemology as defined by Elizabeth Anderson, the role of which she argues is both to proffer feminist critiques of sexist scientific praxis and to legitimate feminis scientific practices. ${ }^{10} \quad$ "Feminist epistemology can be regarded as the branch of social epistemology that investigates the influence of socilly constructed conceptions and norms of gender-specific interests and experiences on the production of knowledge."11 She argues that feminist epistemology is committed to both 'modest empiricism'-"the view... that observation provides the least defeasible evidence we have about the world" - and 'rationality as reflective endorsability, or the conscious and systematic evaluation of our "reason for having any attitude or engaging in any practice of inquiry."12

As such, feminist epistemology raises issu within the pre-established methodology of scientific inquiry: empirical studies and reflective self-correction. The contentions that feminist make cannot responsibly be ignored by scientists who claim to follow sound scientific methodology. In this way, Anderson models feminist epistemological critique on the formation of placebo-controlled, double-blind, multi-center pharmaceutical trials. This method of experimentation arose through the critical work of naturalized epistemology and the evaluation of potential biases in scientific praxis; feminist epistemology, she holds, would function in much the same fashion, except with an emphasis on the influence of gender and other social categories on the biasing of scientific pursuits. ${ }^{13}$

What exactly can feminist epistemology reve about the natural sciences? Anderson break down the focus of feminist epistemology into fou categories: investigations of gender structures in the division of scientific labor, evaluations of gender symbolism in the representation and modeling of inanimate or nonhuman phenomena, exposure of androcentrism in the pursuit of scientific inquiry, and criticisms of sexism in either the content or application of scientific theory ${ }^{14}$ Each of these captegries provides a citique of sience the basis of science's self-correcting thet wodoby; con igne ignored by scientists. Apparently, no matter how much we may try to convince ourselves otherwise, our subjective personal and social situation has a noticeable effect on our 'objective' pursuits.

Nonetheless, one might argue that this is simply a reason why we need to correct constantly for the influence of subjectivity on our "objective" purvits. The underlying asumplon in the porgoing The eprem eping will only detract from our ability to comprehend the truth. While I definitely would not want to be taken to insinuate that I think that gender biases should be acceptable in scientific endeavors-far be it from the truth-I still see problematic traces of the devaluation of subjectivity in this argument. Is the subjective really as universally epistemically invalidating as this analysis would suggest? The next half of this paper will argue that in certain studies, the subjective (or personal) may not only aid, but also be necessary to our effective approximation of the truth..$^{15}$

1. Ibid, 54. Emphasis in the original.

2. Ibid, $51 ; 53$

3. See ibid, 55 .

14. See the remainder of Anderson for a detailed exploration of some of the contribstions of feminis epistenteg in each of these four categories.

15. While I would argue that the subjective can be epistemically valuable for both the social and the natural sciences, it is more immediately evident in the case of the former, and hence the social sciences will be the focus of this claim. For an example of how subjective experience can lead effectively to valid truth-claims in the natural sciences, see Evelyn Fox Keller, Reffections on Gender and Science (New Haven: Yale University Press, 1985). Keller's discussion of the work 
Indeed, the value of subjective experience ranks [with men of Color] when they were so in feminist theory is of central significance: severely "One of the challenges for feminist theory is to and repressive organizations such as the FB begin to document the culturally specific ways and the local police" could have subverted the that gender subordination is imposed."16 I entire Civil Rights movement. ${ }^{19}$ Nevertheless, would argue further that any social science the Civit Rights movement Cid not must take the subjective experiences of its regard their lived experience as women of subjects-who constitute the social sciences' Color

"objects" of inquiry-into consideration..$^{17}$ The While this may not seem like an epistemic epistemic value of subjective experience in my issue on the surface, the oversight can be evaluation extends well beyond just feminist understood as one of epistemic ignorance. theory and the social sciences, but this is beyond The leaders of the feminist movement (white the scope of this paper. ${ }^{18}$ Suffice it to say that women) and the leaders of the Civil Rights subjective experience can be a viable, if not movement (men of Color) both assumed that always necessary, epistemological means to the particular category of oppression that they
ascertaining the truth.

To make this more evident, I offer an example: Aida Hurtado clearly demonstrates that one of the major problems with the "60s and '70s American feminist and Civil Rights movements was the fact that they did not take the full range of personal experience of all members of the group into complete consideration. Women of Color fell in terms of personal identity into both groups, yet neither group took their experience as both
women and racial minorities concomitantly as a basis for political and social thought action, and change. Given the exigencies of the action, and change. Given the exigencies of the situation, women of Color allied themselves with the Civil Rights movement more so than with the feminist movement due to the vital importance of racial solidarity. "[B]reaking put at the forefront of their movement-gender primarily salient issue; they failed to take into account the effect(s) other categories of oppressionwith which they were not personally familiarhad on the oppression of women of Color. In other words, like an example from Hurtado's work, when a white feminist woman looked a a woman of Color, she saw first and foremost a woman; likewise, when a male Civil Rights activist of Color looked at a woman of Color he saw first and foremost a person of Color. The category of oppression that was most salient to their lives became, in their minds, the category of oppression: they generalized from their experience to the experience of women of Color and failed to take into

16. Hurtado, 45. Emphasis added.

17. For example, the misunderstandings of Western anthropological studies of Igbo society described in Nkiru Nzegwu's Family Matters ing the subjective experiences of women, an epistemic error that resulted from the assumption that the men could describe the culture "beter,' and therefore that women's narratives were unimportant to knowledge of the culture. 18. For instance, Little's work shows the centrality of one's subjective experience of one's own emotions in effective moral epistemology and subsequent action based on moral knowledge. Affect provides us a way of seeing the world that yields insight into morality that we

19. Aida Hurtado, The Color of Privilege: Three Blasphemies on Race and Feminism (Ann Arbor: University of Michigan Press, 1996), 103.

account any changes that differences of race or gender might bear on their oppression. What the situation of women of Color called for was a process of "entering her 'world' $-\mathrm{a}$ process very different from accessing other minds through analogical inference", or generalizing to an 'understanding' of the other's experience through analogy to one's own. ${ }^{20}$ Including more viewpoints in the discursive subject position of the theorizer/ knowledge-claimant does more than "correct" inaccurate perceptions of how some individuals understand and experience the world; it also changes and expands how the theorizer/ knowledge-claimant her/himself understands the world. By overlooking the specific personal experience-the subjectivitywomen of Color, these groups both failed to approximate a truthful understanding of their situation that would have benefited the overall cause of their respective movements by creating a more comprehensive view of mechanisms of oppression. Hence, the failur can be considered epistemic.

The importance of the personal has one further implication for epistemology that Hurtado explores: the structure of discourse about knowledge. Hurtado notes that "the broadening of the paradigm of how gender is conceptualized also requires that other materials besides conventional academic production be used to theorize about women of Color."21 Traditional academic work normally entails writing papers for scholarly journals, presenting lectures, discussion panels universities, and so forth. When the object of academia is women of Color from the lowe classes, for instance, ironically the very people being studied are excluded from the production of knowledge, let alone access to the intellectua products of this process. This means that scholars are generating knowledge without even taking into consideration the firsthand accounts of the experience of their subjects. Granted, it is not possible in many cases to do so (e.g. the study of infants or of historical peoples). Nevertheless, whenever access to the direct account of the experience of one's subjects is possible, one should have an epistemic duty, as Hurtado implies, to try to obta accurately the lived experience of one's subjects. With a concept as relative to personal experience as gender, it is necessary to broaden our definitions of what constitutes effective knowledge production.

However, I do not wish to advocate a total shift to the personal, since (certain forms of) the personal will not always be elevant to knowledge production. Toril Moi demonstrates this in her Sex, Gonder, and the Body. Ce person perso have no bearing on the knowledge being sought. The fact that the author of a certain study is having a bad hair day when she writes the study probably has no bearing on the content, methodology, or interpretation of he study. Similarly for the subjects of a study: it is doubtful that their musical preferences will 
have any bearing on that which is being studied the most arrogantly impersonal prose."22 (unless, of course, the object of inquiry is their When considering the language and style of musical preferences). To say that the personal is knowledge communication, "It is impossible often relevant to knowledge production is not to assess the effects of a theoretical style to say that everything personal is categorically without asking who the theory is addressed relevant to knowledge production. relevant to knowledge production. It is the same situation for the this point, to make a blanket assumption about communication of said knowledge. The use the general applicability of the personal is as of certain obscure theoretical language can be epistemically dubious as making a blanket distancing... to some crowds. If I were to give assumption about the impartiality, and hence a presentation to a crowd of art historians, I truth-yielding potentiality, of "objective" would expect them to know what trompe l'oeil natural sciences. In a valid epistemology, the and chiaroscuro are; the same cannot be said context of knowledge dissemination should for a group of kindergarteners visiting their be considered as well as the social context of local museum for the first time. In the same the knowledge producer. fashion, the use of personal information in It may still be claimed by some that the the communication of knowledge can be as introduction of the personal and the subjective distancing or as expedient as the use of technical immediately reduces knowledge to relativism. and obscure terminology can be. If a scholar were Even many feminist epistemologists seem to treat presenting her findings on domestic abuse relativism as a "necessary evil."24 Similar to Moi, to a crowd of survivors of abuse, sharing Sharyn Clough argues, based on the linguistic her personal experience of abuse may help philosophy of Donald Davidson, that "Our beliefs establish a sense of connection between herself have no content unless we have established a and her audience that may in turn allow for a common convergence between ourselves, another greater degree of trust. If she were to deliver speaker (or speakers), and a shared environmental the same story at a sociology conference, more stimulu than likely the situation will become awkward agreeing on a certain set of background beliefs—or and no one will feel comfortable criticizing her as Wittgenstein would say, we must be playing the findings for fear of belittling her experience: same language game in order for any agreement hence all effective intellectual dialogue is or disagreement to be possible. "In the skeptic's stopped. "Explicitly autobiographical and world, the fear that the metaphysical separation emotional writing can be genuinely open between us and the world makes coherent the and revealing or just as "silencing"- just as worry that we are, in principle, unable to speak closed off to engagement from others-as with confidence about the causal links between

22. Toril Moi, Sex, Gender, and the Body: The Student Edition of What Is a Woman? (New York: Oxford University Press, 2005), 248. 22. Toril Moi, 133

24. For a discussion of relativism in the works of Sandra Harding, Evelyn Fox Keller, and Helen Longino, see Sharyn Clough, "A Hasty Retreat From Evidence: The Recalcitrance of Relativism in Feminist Epistemology," Hypatia 13.4 (Fall 1998): 88-111.

25. Ibid, 105. our representations and the world represented."26 However, relativity to a particular conceptual scheme does not necessarily entail absolute relativism, and hence does not entail the inability to stake a truth-claim. Personal or political values can them a lves have verifiable "empirical content that can, in turn, provide good evidential reasons that can, in tum, provide good coidential reasons for rejecting or accepting certain truth-claims. ${ }^{27}$ "The hope of agreement constitutes the aspiration
towards the universal." 28 To assume automatically towards the universal."${ }^{28}$ To assume automatically
that the introduction of the personal or subjective that the introduction of the personal or subjective immediately instantiates inescapable relativism universal is to fall into the trap of the selfsame mutually exclusive objectivity/ subjectivity duality that feminist epistemology is trying to revise.

By wrestling down the dualisms that we use to define self and our relation to the world around us, [feminist epistemologists] make considerable strides toward identifying an epistemology that can ground a common resistance for women without ignoring our important differences. ${ }^{2}$
Through refusing to situate knowledge in an ontological binarism, feminist epistemology structures knowledge with relevance to both the universal and the specific. Epistemic doub should not necessarily be aroused by anything that invokes subjectivity in its methods of should be provoked by the categorzation any knowedge clain as purely objective or the or tally subjective.

In short, no knowledge claim can be purely objective or absolutely relativistic. ${ }^{30}$ Feminis epistemology thus offers us important criticisms and revisions not only of scientific epistemology, but of epistemology in general. In emphas on subjectivity is not uniqu to fenist epistenolicular insights, however, offer much more than simply the tools with which concerned epistemologist may correct dominant methodology. Feminis epistemology proposes a correlate claim with its theory of knowledge that brings more immediate relevance to the pursuit of knowledge. As Hurtado says, "What is appealing about a
26. Ibid, 108.

28. Moi, 236

29. Laura Sells, “Feminist Epistemology: Rethinking the Dualisms of Atomic Knowledge," Hypatia 8.3 (Summer 1993):

30. NB: Just because an experience is uniquely personal does not mean it is completely relativistic. As I hope the above the experience in the first place; commonalities are a prerequisite to understanding, and hence to any kind of disagreement. Likewise for "pure" objectivity: while one may claim that $2+2=4$ universally, this phrase would have no significance if it were uttered in a social context wherein agents did not have either (a) such terminology as part of their intellectual vocabulary or (b) any valuation of the significance of numeration to their lives.

William James's focus on "live" and "dead" options attributes much epistemic gravity claims of feminist epistemology. knowledge-claimant. Additionally, David Annis's contextualism calls attention to the situational construction of methodological norms: certain contexts make certain truth-claims/objections possible, while others may invalidate them a priori. See, respectively, William James, The Will to Believe, and Other Essays in Popular Philosophy (New York: Longman, Greens, and Co,., 1897); and David Annis, "A Contextual Theory of Epistemic Justification," in American Philosophical
Quarterly 15 (1979): $213-219$. 


\section{Rethinking the Binary of Pure Objectivity and Relativistic Chaos}

feminist epistemology ... is the struggle to focus the individual and the universal are not mutually on life and the recognition that humans should exclusive. "An ethics of ambiguity will be one not be oppressed.... [A] feminist epistemology which will refuse to deny a priori that separate assumes that oppression is unnecessary." ${ }^{\prime 2}$ By existants can, at the same time, be bound to each undermining the prospects of "pure" objectivity other, that their individual freedoms can forge on the human level, feminist epistemology laws valid for all." ${ }^{33}$ Essentially, this means that on the haw that eliminates the ability to clain withont doubt "an action which serves man ought to be careful that oppression is ever a natural or inevitable not to forget him on the way." ${ }^{\prime \prime 4}$ I am by no phenomenon of the universe, like some means arguing that any objectivity is impossible, biological determinists controversially claim or that there are no personal experiences that about women's social roles in society. Further, are irrelevant to knowledge creation. Rather, by demonstrating that nothing is relativistic, argue that to hold that only absolutely objective it disallows anybody from categorically methodologies can yield valid truth-claims dismissing, ignoring, or overlooking the or that the personal is universally irrelevant subjective experience of another on the grounds to truth-claims is fundamentally dogmatic subjective experience of another on the grounds to truth-claims is fundamentally dogmatic As

Ultimately, feminist epistemology allows us to

As Beauvoir expresses in her Ethics of expose and to challenge instances of knowledgeAmbiguity, we must learn to live with the as-oppression and to utilize knowledge-asrealization that our existence is founded in liberation: it provides a clear and valuable social essential ambiguities: while every second is a goal to our knowledge production, as well as a moment closer to death, every step towards death means to achieving this end.

is a moment of our lives, and more importantly 